\title{
Pembelajaran Toilet Training bagi Siswa Tunagrahita
}

\author{
Dinda Aryani Pratiwi, Usep Kustiawan \\ Jurusan Pendidikan Luar Biasa Fakultas Ilmu Pendidikan Universitas Negeri Malang \\ E-mail: aryaninda18@gmail.com
}

\begin{abstract}
Abstrak : Tunagrahita adalah seseorang yang memiliki daya pemikiran rendah. Toilet training adalah usaha melatih anak agar mampu mengontrol melakukan Buang Air Kecil (BAK) maupun Buang Air Besar (BAB). Pembelajaran toilet training pada tunagrahita perlu diberikan, mengingat rendahnya intelektual yang menyebabkan kesulitan belajar secara mandiri. Oleh karena itu, pemilihan media dan bahan ajar juga perlu diadakan/dikembangkan. Dalam membelajarkan toilet training pada tunagrahita diantaranya dapat menggunakan buku panduan. Tujuan penelitian ini adalah menghasilkan buku paduan pembelajaran toilet training yang sesuai dengan karakteristik dan kebutuhan siswa tunagrahita. Pengembangan buku panduan ini mengadaptasi langkah-langkah model pengembangan dari Borg and Gall. Buku panduan ini layak dan efektif digunakan dalam proses pembelajaran. Hal ini ditunjukan dari hasil validasi dan uji coba produk. Hasil validasi dari ahli media 91,66\%. ahli materi sebesar 75\%, dan ahli pembelajaran ABK adalah 94,23\%. Hasil rata-rata dari ketiga validasi adalah $86,96 \%$ dengan kriteria sangat valid dan layak untuk digunakan. Hasil uji coba individu adalah $76 \%$ dan hasil uji coba kelompok $76,5 \%$ dengan kategori tinggi dan efektif untuk digunakan dalam pembelajaran.
\end{abstract}

Kata Kunci : Buku Panduan, Toilet Training, Tunagrahita

\begin{abstract}
Student with intellectual disabilities is someone who has low thinking capacity. Toilet training is an effort to train children to be able to control the disposal (BAK) and defecate (BAB). toilet training learning for students with intellectual disabilities needed, because the low intellectual ability possessed by students with intellectual disabilities, therefore the selection of media and teaching materials also need to be held/developed. In teaching toilet training learning on student with intellectual disabilities can use the guidebook. The purpose of this research is to produce instructional guidebook for toilet training that is suitable with the characteristics and needs of students with intellectual disabilities. The research and development of this instructional guidebook use the steps of the development model of Borg and Gall. The results of research and development showed that guidebook was feasible to use in the learning proses. Validation results from media experts $91.66 \%$. Material experts by $75 \%$, and ABK learning experts was $94.23 \%$. The average result of all three validations was $86.96 \%$ with very valid criteria and was feasible to use.
\end{abstract}

Keyword : Guidebook, Toilet Training, Student with intellectual disabilities

Setiap anak memiliki perkembangan yang berbedabeda. Dalam masa perkembangannya tidak menutup kemungkinan terjadi gangguan. Gangguan serius yang sering terjadi pada masa tumbuh kembang anak adalah gangguan bicara, autis, lambat belajar, dan retardasi mental. Retardasi mental atau biasa disebut tunagrahita adalah kondisi seseorang yang memiliki kecerdasan yang rendah dan dibawah rata-rata. Seseorang dikategorikan berkelainan mental subnormal atau tunagrahita, jika memiliki tingkat kecerdasan yang sedemikian rendahnya (di bawah normal), sehingga untuk meniti tugas perkembangannya memerlukan bantuan atau layanan secara spesifik, termasuk dalam program pendidikannya (Efendi, 2009).

Anak tunagrahita dapat diklasifikasikan menjadi tunagrahita ringan, tunagrahita sedang, dan tunagrahita berat. Menururt Soemanti (2012), tunagrahita ringan disebut juga moron atau debil. Kelompok ini memliki IQ 68-52 menurut Binet. Tunagrahita sedang disebut juga imbecil. Kelompok ini memiliki IQ 51-36 pada skala Binet. Tunagrahita Berat sering disebut idiot. Kelompok ini dapat dibedakan lagi antara Tunagrahita Berat dan Sangat Berat. Tunagrahita berat atau severe memiliki IQ antara 32-20 menururt skala Binet dan antara 39 - 35 menurut Skala Weschler (WISC). Tunagrahita Berat atau profound memiliki IQ dibawah 19 menurut skala binet dan IQ dibawah 24 menurut Skala Weschler (WISC).

Dalam pasal 5 ayat 2 Undang-Undang No.20 tahun 2003 tentang Sistem Pendidikan Nasional: "dunia pendidikan adalah untuk menciptakan dan membentuk manusia yang bertakwa, berilmu serta dapat mengembangkan potensi-potensi yang ada untuk direalisasikan dalam kehidupan di masyarakat hal ini berlaku untuk semua anak tanpa memandang keadaan fisik, mental, intelektual, dan atau sosial". Anak tunagrahita mempunyai hak dan kewajiban yang sama dengan anak pada umumnya untuk memperoleh pendidikan. Dengan adanya pendidikan diharapkan anak tunagrahita dapat berkembang sehingga 
dapat menjalani hidup secara mandiri. Cara untuk dengan memberikannya pendidikan melalui lembaga pendidikan yaitu sekolah. Pendidikan yang baik adal pendidikan yang memberikan pelajaran yang bergu baik diluar sekolah dan dalam kehidupan sehari-ha terutama dalam hal untuk membantu siswa mencapa tingkat kemandirianny

Pembelajaran bina diri merupakan pembelajaran yang diharapkan dapat membantu siswa tunagrahita agar dapat mandiri dan tidak bergantung pada orang lain. Bina diri adalah usaha membangun diri individ baik sebagai individu maupun sebagai makhluk sosial melalui pendidikan di keluarga, sekolah da di masyarakat sehingga terwujudnya kemandiria dengan keterlibatannya dalam kehidupan sehari-har secara memadai (Astati, 2010). Pembelajaran bina dir meliputi kemampuan mengurus diri sendiri, seper menggosok gigi, mandi, keramas, serta toilet training.

Toilet Training pada anak merupakan kegiatan yang dilakukan guna untuk melatih anak agar mampu mengontrol dalam melakukan buang air kecil dan buang air besar. Toilet training baik dilakukan sejak dini. kebiasaan baik pada anak. Tidak hanya anak regular saja, tetapi anak dengan hambatan intelektuan ata biasa disebut anak tunagrahitapun perlu untuk diajarka toilet training. Penggunaan kamar mandi (WC) ata toilet training merupakan latihan menggunakan kamar mandi dengan baik dan benar. Dengan toilet training diharapkan agar anak mampu buang air kecil da buang air besar di tempat yang telah ditentukan yaitu kamar mandi (WC). Selain itu mengajarkan anak untuk membersihkan dirinya sendiri setelah buang air keci maupun buang air besar.

Kemampuan anak dalam toilet training sanga berbeda satu anak dengan lainnya. Pembelajara mengenai toilet training pada tunagrhaita memerluka waktu yang relatif lama. Kemampuan intelektual yang rendah, serta lemahnya dalam berfikir hal yang bersifat abstrak menyebabkan pencapaian tujuan pembelajara yang kurang optimal. Pembelajaran toilet training pada tunagrahita harus memperhatikan kondisi anak, mengingat keterbatasan kemampuan berfikir abstrak serta rendahnya kemampuan intelektual yang dimiliki oleh tunagrahita, seorang guru harus bisa memilit metode maupun media pembelajaran bahan ajar yang tepat, terlebih lagi mengenai toilet training tersebut.

Berdasarkan studi pendahuluan diperoleh informasi dari Kepala Sekolah di SMPLB Negeri Kedungkandang bahwa pelaksanaan pembelajaran bina diri di sekolah biasanya dilaksanakan tanp menggunakan media. Siswa sering bosan dan kurang antusias dalam mengikuti pembelajaran Hal tersebut diakibatkan karena model dan metode pembelajaran yang digunakan tidak bervariasi. Gur hanya menggunakan metode demostrasi deng mendeskripsikan analisis tugas sambil mempraktikan dan anak disuruh menirukan yang dipraktikan ole guru

Penggunaan dan pengadaan media saa pembelajaran sangat mempermudah siswa dalam memahami materi pelajaran, yaitu materi yang bersifa abstrak menjadi konkrit. Media yang digunaka untuk membelajarkan bina diri khususnya mengenai toilet training dapat menggunakan buku panduan. Penggunaan buku panduan ini disesuaikan denga karakteristik anak tunagrahita. Kemampuan berfiki rendah anak tunagrahita menjadi alasan perlunya buk panduan dalam pembelajaran. Pembelajaran toile training untuk anak tunagrahita dimaksudkan sebagai bekal dikemudian hari serta anak tunagahita mandir dalam menggunakan toilet.

\section{METODE}

Dalam penelitian dan pengembangan ini mengacu pada strategi penelitian dan pengembangan Borg and Gall. Adapun langkah-langkah pengembangan dari Borg and Gall (1987) adalah (1) research and information collecting, (2) planning, (3) develop peliminary form of product, (4) preliminary field testing. (5) main product revision. (6) main field testing, (7) operational product revision, (8) operational field lesting, (9) final product revision, (10) dissemination testing, (9) final product revision, (10) dissemination implementation.

Langkah penelitian dan pengembangan tersebut bukanlah langkah-langkah baku yang harus diiku

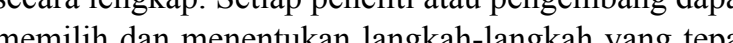
unt diteran sudah ado dalam proses penelition den pengembengen Secara rinci, penelitian dan pengembangan buk panduan pembelajaran toilet training bagi siswa tunagrahita ini melalui beberapa tahap sebagai berikut Pertama penelitian dan pengumpulan informasi. Pad

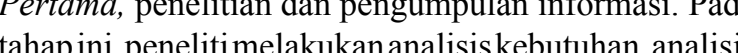
pemilihan bahan ajar, analisis kebutuhan belajor siswa. Kedua, perencanaan. Pada tahap perencanaan, peneli melalukan perumusan tujuan, dan pengemeneliti materi. Perumusan tujuan didasarkan pada kurikulum pembelajaran bina diri. Berdasarkan kompetensi dasa dan standar kompetensi yang terdapat pada kurikulum bina diri. Pengembangan materi dilakukan dengan melakukan konsultasi dengan guru kelas. Penyusune materi didasarkan pada indicator yang akan dicapa oleh siswa. Materi disesuaikan dengan karakteristik dan kebutuhan. Ketiga, pengembangan desain produk awal. Keempat validasi produk awal. Buku panduan yang telah disusun kemudian dinilai oleh ahli media pembelajaran ABK, dan ahli materi. Kelima, revis produk awal. Revisi produk awal merupakan tindak lanjut dari validasi para ahli. Pada tahap revisi produk, perbaikan atau revisi produk awal merupakan sua uapaya yang dilakukan untuk merevisi desain produk dari validator. Keenam, uji coba lapangan. Pada tahap ini uji coba yaitu uji coba individu dan uji coba kelompok. Uji coba bertujuan untuk mengumpulkan data yang dapa digunakan sebagai dasar untuk menetapkan tingka keefektifitas, efisiensi, dan/atau daya tarik dari produk yang dihasilkan. Ketujuh, Revisi produk akhir. Pada tahap yang terakhir adalah pengembang akan melakukan revisi produk yang paling akhir dan berdasarkan hasi uji coba individu dan uji coba kelompok. Revisi produk akhir bertujuan untuk memperbaiki produk agar dapat diterapkan pada siswa secara efektif. Instrumen yang digunakan dalam penelitian ini terdiri dari intrumen dasi dan instrument efektifita

Metode pengumpulan data yang digunakan dalam penelitian ini adalah analisis kebutuhan, analisis pemilihan bahan ajar, dan analisis kebutuhan belajar siswa. Data kualitaif diperoleh dari hasil wawancara dan observasi serta masukan dari validator berupa kritik dan saran. Data kuantitatif diperoleh dar pengisian angket validasi dan uji coba produk berupa porsentase kevalidan buku panduan.

Instrumen pengumpulan data yang digunakan dalam penelitian ini adalah lembar observasi dan wawancer

Analisis data yang digunakan dalam penelitian ini adalah analisis deskriptif untuk data kualitatif berupa saran dan masukan dari validator, serta analisis prosentase untuk data kuantitatif. Data kuantitatif dalam pengembangan ini yaitu data yang diperoleh dari angket validasi dan uji coba. Kriteria skor yang digunakan pada angket validasi yaitu kriteria skor validasi jawaban dari Widoyoko (2013), sedangankan rumus kevalidan buku panduan menggunakan rumus dari Akbar (2016). Selanjutnya, hasil analisis validasi ahli dicocokkan dengan kriteria validitas dari Akbar rumus dari Akbar (2016)

\section{HASIL DAN PEMBAHASAN}

Hasil

Dalam penelitian ini data diperoleh dari hasi validasi produk. Validasi dilakukan oleh ahli media, ahli materi dan ahli pembelajaran ABK. Hasil analisis dan pengolahan data validasi ahli media diperoleh hasil $100 \%$. Dilihat dari kriteria kelayakan yang ditentukan dapat dikategorikan Sangat Valid atau layak digunakan. Meskipun hasil validasi dari ahli media menunjukkan bahwa buku panduan layak digunakan, validato tap memberikan saran. Adapun saran dari validator yaitu, 1) pada sampul belakang buku sebaiknya diber dikarenakan produk buku panduan masih polos, 2) permpuan, 3) praking dibedakan training duduk aupun jongkok secara keseluruhan sebaiknya diberi keteranga

Hasil validasi ahli pembelajaran $\mathrm{ABK}$ di diperoleh hasil 94\%. Dilihat dari kriteria kelayakan yang ditentukan bahwa buku panduan pembelajaran toilet training dapat dikategorikan Sangat Valid atau dapat digunakan dalam proses pembelajaran toilet training

Saran dari ahli pembelajaran ABK adalah adalah merevisi soal evaluasi untuk siswa.

Hasil analisis dan pengolahan data validasi hli materi diperoleh hasil $75 \%$. Dilihat dari kriteria kelayakan yang ditentukan bahwa buku panduan pembelajaran toilet training dapat dikategorikan Cukup id atau dapat digunakan, namun perlu revisi kecil.

Saran perbaikan dari ahli materi adalah (1) buku panduan sebaiknya dibedakan untuk perempuan dan laki-laki, (2) pada setiap gambar diberi keterangan, (3) untuk tes kinerja/praktik pembelajaran toilet diting sebaiknya langkah-langkah perintah/petunjuk tiambah, (4) pada tahapan melepas celana sebaiknya baju sehingga posisi ank saat berada dikloset jongkok

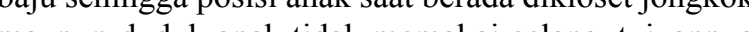
maupun duduk anak tidak momaki celana, tujuannya

Kesimpulan tingkat kelayakan buku panduan pembelajaran toilet training secara keseluruhan dapat dianalisis dengan menghitung jumlah skor yang diperoleh dari ketiga validator yaitu, ahli media, ahli pembelajaran ABK, dan ahli materi dengan menggunakan rumus dari (Akbar, 2016:83). Hasil skor validasi dari ketiga ahli adalah $90 \%$. skor tersebut menunjukkan bahwa Buku Panduan Pembelajaran Toilet Training Bagi Siswa Tunagrahita yang dikembangkan dalam penelitian ini sangat layak dan dapar dignnakan dalan penbelajaran Bina Diri

Uji coba produk buku panduan dalam penelitian dan pengembangan ini dilakukan melalui dua tahap yaitu uji coba individu dan uji coba kelompok. Hasil uji coba individu diperoleh nilai 60 pada tes pengetahuan dan 92 pada tes Kinerja/praktik. Nilai kemudian diratarata dan diporsentasekan diperoleh hasil 76\%. Jika melihat kriteria keefektivitas produk, maka hasil uji coba individu masuk ke dalam kategori tinggi atau efektif, artinya buku panduan pembelajaran toilet training bagi siswa tunagrahita di SMPLB Negeri Kedungkandang Malang dinyatakan Efektif untuk

hasil analisis uji coba kelompok yang disajikan . Jika mengacu pada kriteria keefektivitas produk, maka tau efektif, artinya buku panduan pembelajaran toilet training efektif untuk digunakan dalam pembelajaran 


\section{Pembahasan}

Penelitian dan pengembangan buku panduan ini berangkat dari permasalahan siswa tunagrahita yang masih belum mampu dalam menggunakan toilet. Toile training merupakan suatu kegiatan melatih anak aga umumnya kegiatan toilet training diajarkan pada anak ketika umur balita begitupun kepada anak dengan hambatan intelektual (tunagrahita). Namun pad kenyataannya masih ada siswa tunagrahita yang masi belum dapat menggunakan kamar mandi dengan baik. Masalah yang sering dialami oleh siswa tunagrahita adalah pada saat sedang BAK/BAB pintu kamar mandi tidak di tutup. Selain itu siswa tunagrahita tidak menjaga kebersihan sekitar kloset. Sulitnya siswa tunagrahita dalam memahami materi menyebabka guru harus berulang-ulang dalam memberika instruksi. Oleh karena itu dalam memberikan mate pembelajaran kepada siswa tunagrahita sebaiknya menggunakan media. Pengadaan dan penggunaa media dalam pembelajaran sangat mempermuda siswa dalam memahami materi yang sedang dipelaja Adapun media yang digunakan dapat berupa gamb seri, kartu bergambar maupun menggunakan buk panduan. Pengembangan buku panduan ini meruju pada skripsi karya Indrawati (2014) yang menyebutka bahwa buku panduan efektif digunakan dalam proses pembelajaran.

Buku panduan pembelajaran toilet training in merupakan inovasi baru yang dapat dijadikan media pembelajaran dalam proses pembelajaran bina diri khususnya toilet training. Buku panduan ini dibua sejalan dengan media gambar yang dikembangka menjadi buku panduan. Sejalan dengan penelitia sebelumnya karya Rifqy (2014) yang menjelaska bahwa media gambar memberikan pengaruh terhadap kemampuan siswa dalam berbelanja.

Buku panduan pembelajaran toilet training dirancang merujuk pada pendekatan analisis tugas. Kustawan dan Yanti (2014) mengemukakan analisis tugas adalah upaya mengadakan rincian dari satu keterampilan mejadi langkah-langkah atau tugas-tugas kecil yang memungkinkan peserta didik mudah untuk melaksanakannya. Sejalan dengan Panjaitan, dkk (2013) yang menunjukan bahwa adanya peningkata kemampuan toilet training dalam melakukan buang air kecil anak tunagrahita

Keunggulan dari pengembangan buku pandua pembelajaran toilet training ini dapat dilihat dai kemenarikan media yang disertai dengan gambar dan keterangan. Gambar sangat memudahkan siswa dalam memahami langkah-langkah dalam pembelajaran toile

training. Gambar adalah media visual dalam bent grafis. Media grafis didefinisikan sebagai media yang mengkombinasi fakta melalui suatu kombinasi pengungkapan kata-kata da gambar-gambar (Sudjana, 2007). Selain itu keunggula dari buku panduan dapat dilihat dari kesederhanaa materi yang disajikan sehingga mempermudah siswa dalam memahami materi yang dipelajari.

\section{PENUTUP}

\section{Kesimpulan}

Berdasarkan hasil validasi produk diperoleh skor skor tersebut masuk ke dalam kategori sangat ting dengan kriteria kevalidan sangat valid. Hasil uji coba individu diperoleh nilai 60 pada tes pengetahuan da 92 pada tes kinerja/praktik. Nilai kemudian dirata-ra dan diporsentasekan diperoleh hasil 76\%. Dari hasil validasi, uji coba individu dan uji coba kelompo dapat simpulkan bahwa buku panduan pembelajaran toilet training bagi siswa tunagrahita layak dan efektf digunakan dalam proses pembelajaran.

\section{Saran}

Saran yang diajukan peneliti ditinjau dari pemanfaatkan diharapkan buku panduan pembelajaran toilet training dapat digunakan sebagai media training. Untuk saran pengembangan lebih lanjut, dapat dilakukan melalui penelitian kuantitatif dengan memanfaatkan buku panduan. Tujuannya untuk mengetahui apakah ada pengaruh buku pandua terhadap peningkatan kemampuan siswa tunagrahit dalam pembelajaran toilet training. Selain itu, sebaiknya validator lebih dari satu orang agar produk yang dihasikan lebih layak dan sempurna untuk digunakan dalam pembelajaran.

\section{DAFTAR RUJUKAN}

Akbar, S (2016) Instrumen Perangkat Pembelajaran. Bandung: PT Remaja Rosdakarya.

Astati. (2010). Bina Diri Untuk Anak Tunagrahita. Bandung. Catur Karya Mandiri

Azizah, R.S. (2014). Peningkatan Keterampilan Berbelanja Siswa Tunagrahita Kelas VI Dengan Menggunakan Media Gambar Di SLB Kemala Bhayangkan Trengalek. Skripsi tidak Universitas Negri Makulas W.R. \& Gall, M. D.

Borg, W.R., \& Gall, M. D. (1983). Educationa Research: An Introduction. New York: Longma

Efendi, M. (2009). Pengantar Psikopedagogik Anak Berkelaianan. Jakarta: PT. Bumi Aksara
Indrawati, R.D. (2014). Pengembangan Buku Panduan Pengemasan Sayur Organik Bagi siswa Tunagrahita Ringan SMPLB di SLB PTN Bagian $C$ Lawang Malang. Skripsi tidak diterbitkan. Malang: Fakultas Ilmu Pendidikan Universitas Negeri Malang

Kustawan, D \& Yanti L. (2014). Program Pengembangan Diri Untuk Peserta Didik Tunagrahita. Jakarta: Direktorat Jendral Pendidikan Dasar Kementerian Pendidikan dan Kebudayaan

Soemantri, S. (2012). Psikologi Anak Luar Biasa. Bandung: Refika Aditama
Panjaitan, R. Dkk. (2013). Meningkatkan Kemampuan Toilet Training Melalui Analisis Tugas Pada Anak Tunagrahita Sedang. Jurnal Pendidikan Khusus Volume 2 Nomor 3 September 2013

Sudjana. (2007). Media Pengajaran. Jakarta: Sinar Baru Algesindo

Sukmadinata, N.S. (2016). Metode Penelitian Pendidikan. Bandung: PT Remaja Rosdakarya

Undang-Undang Dasar RI No. 20 Tahun 2003 tentang Sistem Pendidikan Nasional. Online (Available
http://sindikker.dikti.go.id/dok/UU/UU20-2003Sisdiknas.pdf ) diakses tanggal 22 Februari 2017 